\title{
Taking Stock - the Process and Benefits of Performing a Regular Library Stocktake by Kerrie Stevens
}

S tocktaking is a valuable part of library work. It maintains collection quality and makes the collection accessible and relevant. It ensures that your catalogue accurately reflects what is on the shelves in the library. A once-a-year stocktake allows every item to be physically handled, mended, repaired, re-catalogued or removed, if required. Stocktaking also allows for everything to be in its rightful place, in perfect order, at least for five minutes until a user comes in to use something!

Some libraries perform a stocktake on a section-by-section basis, others do the entire collection in one go. This year during my annual stocktake procedure, I did a few things differently and had some unexpected, but pleasantly surprising and pleasing results.

Prior to beginning my stocktake, I requested that all loans from students, especially those graduating, and non-essential loans from staff were returned. This enables me to 'fit' the collection on the shelves correctly, rather than guessing how much room I need for each Dewey area. It also provides less of a chance for items to disappear under beds during the holiday season, never to be seen again. After the final date for loans to be returned, I allow one more 'secret' week, as there are always a few stragglers that can never seem to get stuff back by the day they have been told. Then I am ready to begin!

It is not necessary to close the library during a stocktake. However, during my annual stocktake, I prefer to close the library to students, most of whom have finished their studies anyway, and only allow staff members to use the library if they really need to. This ensures the collection I have already stocktaked stays in the correct shelf order for as long as possible.

"Stocktaking and weeding are two activities that are often not highly publicised outside the library environment and are not well understood by non-library staff." ${ }^{\text {Other staff }}$ members just don't get why I love to do my annual stocktake - even my husband calls me a 'major nerd'! I love putting things in order and for that to be successful, it can't be messed up by students and staff browsing the shelves, removing items and putting them back wherever they like. Closing the library gives me the assurance that it will stay in order at least until I re-open - even if it is only $1-2$ weeks later.

\section{The Process}

The first step for my stocktake, is to LOCK the library door - even if the sign says CLOSED, you will find people still coming in just because they want to borrow that one book. If you can isolate the lights so only the section you are working in can be lit, even better!

\footnotetext{
Renate Beilharz, "Secret library business," Connections 62 (2007), accessed December 10, 2010, http://www2. curriculum.edu.au/scis/connections/issue_62/secret_library_business.html
} 
"To begin the stocktake, I must initialise the areas I wish to enter within my catalogue software. ... When barcodes are entered, if they haven't been initialised, they will be picked up immediately in the incorrect spot on the shelf."
Be ruthless and ignore the knocks on the door - turn your music up loud so you can't hear them. Your job is to scan the collection, so scan the collection.

To begin the stocktake, I must initialise the areas I wish to enter within my catalogue software. For smaller areas in the collection, it is easy to do them all in one go (e.g. Reference, DVDs), but for the larger lending collection, I initialise row by row. This may sound fiddly, but there is a very valid reason for doing it this way. When barcodes are entered, if they haven't been initialised, they will be picked up immediately in the incorrect spot on the shelf. This happened several times with this year's stocktake.

Whilst scanning every item in a particular bay of shelves, I would also put them into correct shelf order. This is easier said than done and why the initialising of small sections comes in handy. After looking at call numbers all day, even I was surprised at how many obviously mis-shelved items I missed during the shelf tidy. After the data entry of each bay of shelves, the mis-shelved items were able to be located and placed in the correct location.

There were also a number of items this year located with the incorrect call number label attached. In over eight years of stocktakes, they had never been located until this year, so it was very rewarding to find them and give those items the correct labels. These were again found because of the small initialisation ranges.

Another part of this year's stocktake was moving the entire collection across into some newly acquired shelving bays. These new bays would ease the compression of the collection on the shelves, and provide a small amount of growth space for the next few years. To do this, I would scan a row of books, then move them to the new row of shelves, make sure they are in the correct order and continue with the next row of shelves. I ensured that I left approximately $15-20 \mathrm{~cm}$ of spare space at the end of each row, with the odd row left completely empty for future expansion. Siems and Demmers describe the "optimum capacity for a working collection requires shelves that are only 70 to $75 \%$ full. This extra space is not considered future growth space, but is the space required for collection management, efficient re-shelving, interfiling of new acquisitions and multi-volume sets." ${ }^{2}$

As part of moving the entire collection around to incorporate the new shelving, I was able to have some empty shelves to bring the collection into and therefore adjust the shelves to allow for height differences in items. Prior to the shelving move, some items had been folded over or shelved on their spines so they would fit into the shelves - now they all line up perfectly because I could adjust the shelving heights appropriately without having to remove all the items across several shelves - many of our bays share shelving joiners, making moving a single shelf impossible.

2Earl Siems and Linda Demmers, Library Stacks and Shelving (California: Libris Design Project, n.d.), accessed December 10, 2010, http://www.librisdesign. org/docs/ShelvingforLibraries.pdf, 4. 
"There were a few

things that have

worked out well for

the performance of

a stocktake at my

library. Some have

been planned, but

others just worked

out that way, which

I am very pleased

about."
Some of the many benefits of stocktaking are:

- Putting the collection in correct shelf order

- Locating mis-shelved items and correctly re-shelving them

- Locating incorrectly labelled items and re-labelling them

- Locating previously missing items

- Making space on the shelves for future growth of the collection

- Adjusting shelves in between putting books onto the shelves, eg: height adjustments for those slightly taller books

- Locating multiple copies at different locations and rectifying on the catalogue

- Accurately reporting collection holdings and missing items

- Locating items still out on loan for removal from students/ staff circulation accounts - they've probably been charged overdue fines for books that are back on your shelves!

\section{Stocktake Considerations}

There were a few things that have worked out well for the performance of a stocktake at my library. Some have been planned, but others just worked out that way, which I am very pleased about. One thing that has been planned over the last few years, are the call number labels. I started updating the old, faded and unreadable call number labels about 5 years ago. This has benefited me in a number of ways, especially during the stocktake period. I can quickly and easily glance at the shelves and see which items have not been used for more than 5 years. My new labels are clear, easy to read and the entire number can be seen on the spine of the book, even if it is less than $1 \mathrm{~cm}$ thick. This makes shelf-reading so much easier.

Things to consider in preparing your library for stocktake:

- Where are the barcodes located on your items? Mine are mostly on the lower-right back cover which means I don't have to physically remove every item from the shelf to scan it. I can just stick it out a little, scan the barcode, and move on. If your barcodes are not located in such an easy position, (for example, if they are on the inside of the cover) then your stocktake will take much longer as you will have to physically open every book to scan it.

- A portable barcode scanner is very helpful. This allows me to go to the shelves and scan all the items in a bay before returning to my computer to load the barcodes. If you didn't have a portable barcode scanner, you still have a few options: you could hire one; or you could load your computer onto a trolley and wheel it around the shelves, with a long extension cord this would be another reason for closing the library - OH\&S issues! Prior to my starting in my current position, the librarian used to carry the books to the computer at the front desk, scan them and then carry them back - no wonder a stocktake wasn't done all that often! 
"At the end of the stocktake, after everything has been scanned, searched for, located and relocated, the stocktake is finalised.... If something has been missing from my collection for more than 5 years, it is purged from the catalogue, as the chances of it turning up are pretty slim."
- Consider updating your call number labels - even if it is only on the books that are being returned, and you'll soon be able to see easily which books are being used, and which aren't. This has the added benefit of being useful when it is time to do some collection weeding.

- If you have as much of the collection returned as possible, you can accurately allow the correct amount of space in the right areas. All those 5 volume sets will come back one day, and if you didn't know where they go, how will you have known to leave a little extra space in that particular Dewey section?

- Have some good music to scan to. Every year I get out my $\mathrm{CD}$ player and radio and crank up some groovy tunes or listen to the cricket whilst scanning my barcodes. It helps make the time fly by. You can even scan to the beat if it's not too fast!

At the end of the stocktake, after everything has been scanned, searched for, located and relocated, the stocktake is finalised. I have the option of purging missing items after a certain time period. If something has been missing from my collection for more than 5 years, it is purged from the catalogue, as the chances of it turning up are pretty slim. Missing items do, however, turn up occasionally. This is why I leave the records on the catalogue for a few years. This year we actually had less missing items than last year, so some turned up from somewhere!

The final report I produce is a very useful report. It contains the following data:

- Number of items in collection - this year and last year which enables you to work out a \% increase (or decrease) in the collection. It is divided into collection areas (eg: Reference, DVDs, maps, lending collection, with a total for the entire collection at the end)

- Number of missing items from this year and last year for a $\%$ comparison

- Number of items in collections at different campuses

- Number of borrowers registered in the library catalogue - a useful statistic for the ANZTLA statistics questionnaires

- Number of loans performed throughout the year - again, a useful statistics for the ANZTLA statistics questionnaires

- Serial subscriptions and databases - again, for the ANZTLA statistics questionnaires

Compiling these statistics at the end of the year when it is usually quieter and easier means that when the ANZTLA statistics questionnaires come out in April or May the following year, the data is there ready to be transferred across and reports don't have to be run during the busy semester.

So I hope this article has informed you about why it is a good idea to perform a library stocktake on your collection, and given you some ideas about how you could do it. Go on, give it a go! 


\section{Bibliography}

Beilharz, Renate. "Secret library business." Connections, no. 62 (2007). Accessed December 10, 2010. http://www2.curriculum. edu.au/scis/connections/issue_62/secret_library_business.html.

Siems, Earl and Linda Demmers. Library Stacks and Shelving. California: Libris Design Project, n.d.. Accessed December 10, 2010. http://www.librisdesign.org/docs/ShelvingforLibraries.pdf.

"Go on,

give it

a go!" 